NASA/TM-2007-214996

AIAA-2007-6775

\title{
Crew Exploration Vehicle Ascent Abort Trajectory Analysis and Optimization
}

Robert D. Falck and Leon P. Gefert

Glenn Research Center, Cleveland, Ohio 


\section{NASA STI Program . . . in Profile}

Since its founding, NASA has been dedicated to the advancement of aeronautics and space science. The NASA Scientific and Technical Information (STI) program plays a key part in helping NASA maintain this important role.

The NASA STI Program operates under the auspices of the Agency Chief Information Officer. It collects, organizes, provides for archiving, and disseminates NASA's STI. The NASA STI program provides access to the NASA Aeronautics and Space Database and its public interface, the NASA Technical Reports Server, thus providing one of the largest collections of aeronautical and space science STI in the world. Results are published in both non-NASA channels and by NASA in the NASA STI Report Series, which includes the following report types:

- TECHNICAL PUBLICATION. Reports of completed research or a major significant phase of research that present the results of NASA programs and include extensive data or theoretical analysis. Includes compilations of significant scientific and technical data and information deemed to be of continuing reference value. NASA counterpart of peer-reviewed formal professional papers but has less stringent limitations on manuscript length and extent of graphic presentations.

- TECHNICAL MEMORANDUM. Scientific and technical findings that are preliminary or of specialized interest, e.g., quick release reports, working papers, and bibliographies that contain minimal annotation. Does not contain extensive analysis.

- CONTRACTOR REPORT. Scientific and technical findings by NASA-sponsored contractors and grantees.
- CONFERENCE PUBLICATION. Collected papers from scientific and technical conferences, symposia, seminars, or other meetings sponsored or cosponsored by NASA.

- SPECIAL PUBLICATION. Scientific, technical, or historical information from NASA programs, projects, and missions, often concerned with subjects having substantial public interest.

- TECHNICAL TRANSLATION. Englishlanguage translations of foreign scientific and technical material pertinent to NASA's mission.

Specialized services also include creating custom thesauri, building customized databases, organizing and publishing research results.

For more information about the NASA STI program, see the following:

- Access the NASA STI program home page at http://www.sti.nasa.gov

- E-mail your question via the Internet to help@sti.nasa.gov

- Fax your question to the NASA STI Help Desk at 301-621-0134

- Telephone the NASA STI Help Desk at 301-621-0390

- Write to: NASA Center for AeroSpace Information (CASI) 7115 Standard Drive Hanover, MD 21076-1320 
NASA/TM-2007-214996

AIAA-2007-6775

\section{Crew Exploration Vehicle Ascent Abort Trajectory Analysis and Optimization}

Robert D. Falck and Leon P. Gefert

Glenn Research Center, Cleveland, Ohio

Prepared for the

Guidance, Navigation and Control Conference and Exhibit

sponsored by the American Institute of Aeronautics and Astronautics

Hilton Head, South Carolina, August 20-23, 2007

National Aeronautics and

Space Administration

Glenn Research Center

Cleveland, Ohio 44135 
This report is a formal draft or working paper, intended to solicit comments and ideas from a technical peer group.

This report contains preliminary findings, subject to revision as analysis proceeds.

This report is a preprint of a paper intended for presentation at a conference.

Because changes may be made before formal publication, this preprint is made available with the understanding that it will not be cited or reproduced without the permission of the author.

Level of Review: This material has been technically reviewed by technical management.

Available from

NASA Center for Aerospace Information 7115 Standard Drive

Hanover, MD 21076-1320
National Technical Information Service 5285 Port Royal Road Springfield, VA 22161 


\title{
Crew Exploration Vehicle Ascent Abort Trajectory Analysis and Optimization
}

\author{
Robert D. Falck and Leon P. Gefert \\ National Aeronautics and Space Administration \\ Glenn Research Center \\ Cleveland, Ohio 44135
}

\begin{abstract}
The Orion Crew Exploration Vehicle is the first crewed capsule design to be developed by NASA since Project Apollo. Unlike Apollo, however, the CEV is being designed for service in both Lunar and International Space Station missions. Ascent aborts pose some issues that were not present for Apollo, due to its launch azimuth, nor Space Shuttle, due to its cross range capability. The requirement that a North Atlantic splashdown following an abort be avoidable, in conjunction with the requirement for overlapping abort modes to maximize crew survivability, drives the thrust level of the service module main engine. This paper summarizes 3DOF analysis conducted by NASA to aid in the determination of the appropriate propulsion system for the service module, and the appropriate propellant loading for ISS missions such that crew survivability is maximized.
\end{abstract}

\section{Nomenclature}

$\begin{array}{ll}\text { 3DOF } & \text { 3 Degrees of Freedom } \\ \text { ATO } & \text { Abort to Orbit } \\ \text { CARD } & \text { Constellation Architecture Requirements Document } \\ \text { CEV } & \text { Crew Exploration Vehicle (Orion) } \\ \text { CLV } & \text { Crew Launch Vehicle (Ares I) } \\ \text { CM } & \text { Crew Module } \\ \text { CONUS } & \text { Continental United States } \\ \text { DAEZ } & \text { Downrange Abort Exclusion Zone } \\ \text { fps } & \text { Feet per second } \\ \text { ft } & \text { Feet } \\ \text { ISS } & \text { International Space Station } \\ \text { LAS } & \text { Launch Abort System } \\ \text { lbf } & \text { Pounds force } \\ \text { MET } & \text { Mission Elapsed Time } \\ \text { nmi } & \text { Nautical Miles } \\ \text { OME } & \text { Orion Main Engine } \\ \text { RCS } & \text { Reaction Control System } \\ \text { SM } & \text { Service Module } \\ \text { TAL } & \text { Targeted Abort Landing } \\ \text { UAS } & \text { Untargeted Abort Splashdown }\end{array}$

\section{Introduction}

The Constellation Architecture Requirements Document (CARD) ${ }^{1}$ stipulates that there shall be no period during a mission in which a survivable abort mode is not available to the crew. It also requires that no abort mode shall land the crew module $(\mathrm{CM})$ in the North Atlantic Ocean more than $150 \mathrm{nmi}$ from St. John's, Newfoundland or Shannon, Ireland; the so-called North Atlantic Downrange Abort Exclusion Zone (DAEZ). This means that a Targeted Abort Landing (TAL) or Abort-to-Orbit (ATO) shall be possible when the ballistic impact point of the vehicle exceeds $150 \mathrm{nmi}$ from St. John's, Newfoundland, preferably with several seconds of overlap such that multiple abort modes are available. As a result of this requirement, the CEV must be designed such that the Service 
Module (SM) has enough thrust and enough propellant to loft the CEV CM near Ireland once an eastern seaboard landing is no longer available. Such considerations were not necessary during Apollo since the restrictions on rescue time are a result of the orbital inclination of International Space Station (ISS), which requires an ascent ground track through the North Atlantic. The Space Shuttle's aerodynamic properties give it much greater downrange and crossrange capability than a capsule design, and combined with its ascent profile this means the Shuttle propulsion system was not driven by the need to avoid the North Atlantic.

There has been some question as to the appropriate propellant loading for the ISS mission. Loading the propellant so as to provide enough delta-V capability for an ATO as early as possible seems reasonable, since the abort-to-orbit is presumably less risky to the crew and less costly in terms of recovery, provided it allows for a CONUS landing. However, the relatively low loft of the Ares-I launch vehicle, coupled with concerns of aerodynamic heating in the upper atmosphere during an abort, means the earliest TAL or ATO capability of the $\mathrm{CEV}$ will be strongly affected by the thrust-to-weight ratio of the vehicle. Therefore it seems reasonable that using a lighter propellant loading to allow for TAL aborts as early as possible might be necessary in order to provide for continuous abort coverage during launch and avoid violation of the DAEZ, even at the expense of delayed ATO abort coverage.

\section{Analysis}

Two propellant loadings are assessed. The propellant loading which maximizes TAL coverage (or provides the earliest possible TAL abort) will be referred to as Max-TAL. The propellant loading which provides the earliest possible ATO capability will be referred to as Max-ATO. The Max-TAL propellant loading should be less than Max-ATO propellant loading, since the delta-V associated with TAL is significantly less than that of ATO at a given abort initiation time. With a lower propellant loading, the CEV has a greater thrust-to-weight ratio, and thus should be able to perform the TAL abort earlier. Once the Max-TAL propellant loading is determined, an ATO case using the Max-TAL propellant loading is analyzed and the minimum abort time assessed. This provides the opening of the TAL and ATO windows when using the Max-TAL propellant loading. Similarly, once the Max-ATO propellant loading is determined, the earliest possible TAL abort using that propellant loading is determined.

For each of the two propellant loadings, five abort thrust magnitudes are examined: $7500 \mathrm{lbf}, 8300 \mathrm{lbf}, 10000$ lbf, $10800 \mathrm{lbf}$, and $10980 \mathrm{lbf}$. These represent various combinations of main engine and abort auxiliary engine thrust levels. Different masses of the various propulsion system options are not considered. The specific impulse of the propulsion system for each case examined is 323 seconds. The final weight of the combined CM and SM after an abort is fixed based on the dry-mass of the CEV configuration being examined. The ATO model also reserves an additional $250 \mathrm{fps}$ for deorbit, whereas the TAL model is allowed to exhaust all usable propellant.

\section{A. Abort Mode Models and Assumptions}

Three modes of abort are considered in this analysis. Since this analysis is concerned with system-design impacts of the North Atlantic Downrange Abort Exclusion Zone (DAEZ) requirement, aborts enabled by the Launch Abort System (LAS) are not considered, since the LAS is jettisoned before the DAEZ becomes an issue.

Untargeted Abort Splashdown (UAS) type aborts; referred to as Mode II aborts during Apollo ${ }^{2}$, use the service module (SM) reaction control system (RCS) thrusters to separate from the Ares I upper stage. In general, thrusting from the SM is not required to influence the landing point of UAS aborts, although doing so may be considered in some cases. Thrusters on the crew module control the vehicle's bank angle during reentry, which in turn controls the lift vector and can be used to guide the vehicle to some extent. In this analysis, the bank angle is allowed to vary dynamically such that the acceleration levels experienced by the crew did not exceed 10 gees. For Orion missions to ISS, UAS aborts will result in a water recovery of the crew off of the Atlantic coast of the United States or Canada. This abort mode ends when the landing point of the CM is $150 \mathrm{nmi}$ east of St. John's, Newfoundland. This range is based on assumptions regarding the speed and range of helicopter or other recovery assets located at St. John's International Airport. While this abort mode does not directly impact the sizing of the Orion Main Engine (OME), the latest possible UAS abort defines the point where TAL or ATO aborts must be possible, otherwise a gap in abort coverage or a recovery from the DAEZ will result. Table 1 shows the phase sequence used to model the UAS abort mode. A notional flight profile of a UAS abort is shown in Figure 1. 
Table 1. Untargeted abort splashdown phase sequence

\begin{tabular}{|c|l|}
\hline Phase & \multicolumn{1}{c|}{ Description } \\
\hline Abort Initiation & $\begin{array}{l}\text { Abort is initiated at a give time }\left(\mathrm{t}_{0}\right) . \\
\text { The CEV state is assigned based on the interpolated CLV state at } \mathrm{t}_{0 .} . \\
\text { CEV coasts to reentry interface. }\end{array}$ \\
\hline Reentry & $\begin{array}{l}\text { CM is separated from SM at the reentry interface. } \\
\text { The initial bank and yaw angles at the reentry interface is } 0^{\circ} \text { (lift up). } \\
\text { The initial pitch angle is interpolated from the trimmed aerodynamic database based on } \\
\text { Mach number. } \\
\text { CM reenters the atmosphere. The bank angle on reentry is allowed to vary from }-90^{0} \text { to } \\
90^{0} \text {. The bank angle is optimized such that abort initiation may occur as early as } \\
\text { possible while still landing within } 150 \text { nmi of St. John's International Airport, and } \\
\text { maintaining a total acceleration on the vehicle of less than } 10 \text { gees. }\end{array}$ \\
\hline
\end{tabular}

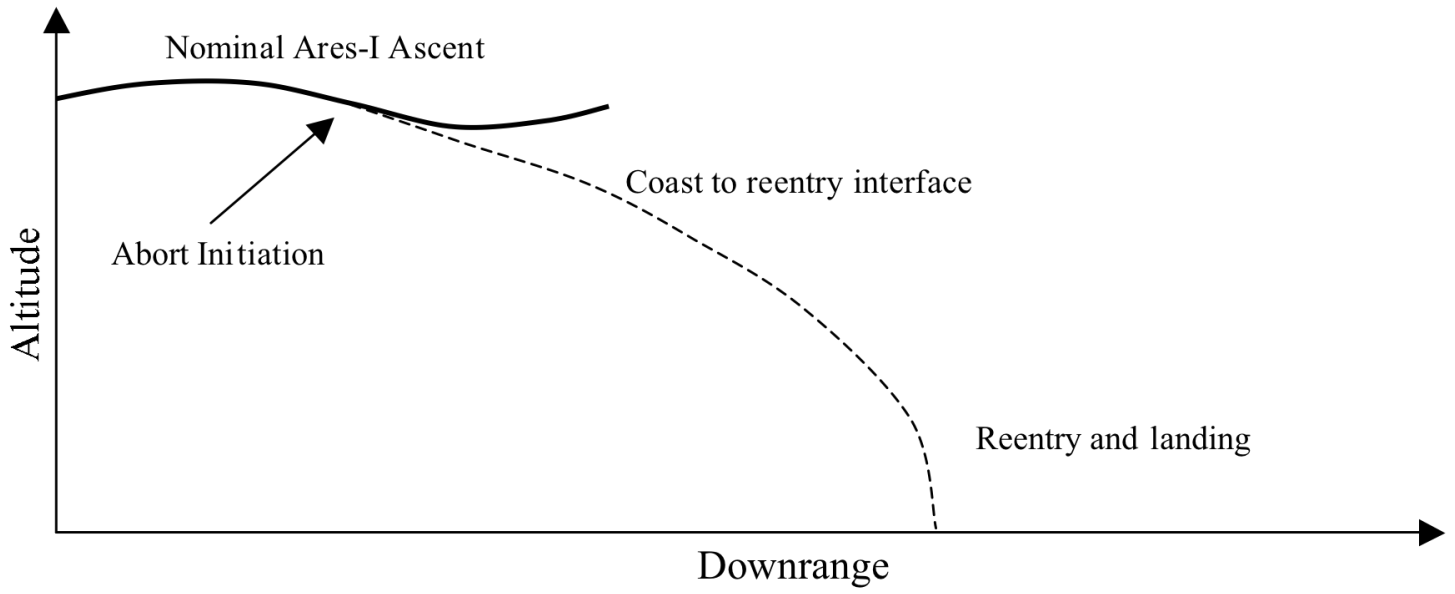

Figure 1. Untargeted abort landing flight profile

TAL aborts, referred to as Mode III aborts during the Apollo program ${ }^{2}$, use the SM RCS system to separate from the Ares I upper stage, followed by a firing of the OME to boost the crew module landing point to within $150 \mathrm{nmi}$ of Shannon, Ireland. These aborts begin as soon as the SM propulsion system is able to provide the required delta- $\mathrm{V}$ while maintaining a minimum altitude sufficient to avoid excessive heating. Previous analysis has suggested that a 400,000 ft minimum altitude constraint provides an acceptable level of aerodynamic heating while minimizing the penalty to the Ares-I payload capability. In this analysis, reentry is done using a 'lift-up' attitude. This provides the maximum downrange capability for the reentry, and thus facilitates initiating an abort as early as possible. Table 2 shows a summary of the five phases used in the formulation of TAL within the trajectory optimization software, and Figure 2 shows a notional TAL flight profile.

Table 2. TAL abort phase sequence

\begin{tabular}{|c|c|}
\hline Phase & Description \\
\hline Abort Initiation & $\begin{array}{l}\text { Abort is initiated at a give time }\left(t_{0}\right) \text {. } \\
\text { The CEV state is assigned based on the interpolated CLV state at } t_{0} \text {. }\end{array}$ \\
\hline Separation & CM is separated from SM and the vehicle drifts for 15 seconds. \\
\hline Main Engine Burn & $\begin{array}{l}\text { The main engine and auxiliary thrusters are fired to boost the downrange landing } \\
\text { point into the TAL recovery area, while maintaining an altitude above the droop } \\
\text { altitude constraint }(400,000 \mathrm{ft}) \text {. }\end{array}$ \\
\hline Reentry Interface & The vehicle coasts to the reentry interface, defined as $300,000 \mathrm{ft}$ altitude. \\
\hline Reentry & $\begin{array}{l}\text { The vehicle reenters the atmosphere using a 'lift-up' attitude, deploys parachutes at } \\
\text { approximately } 50,000 \mathrm{ft} \text {, and lands near the TAL recovery area. }\end{array}$ \\
\hline
\end{tabular}




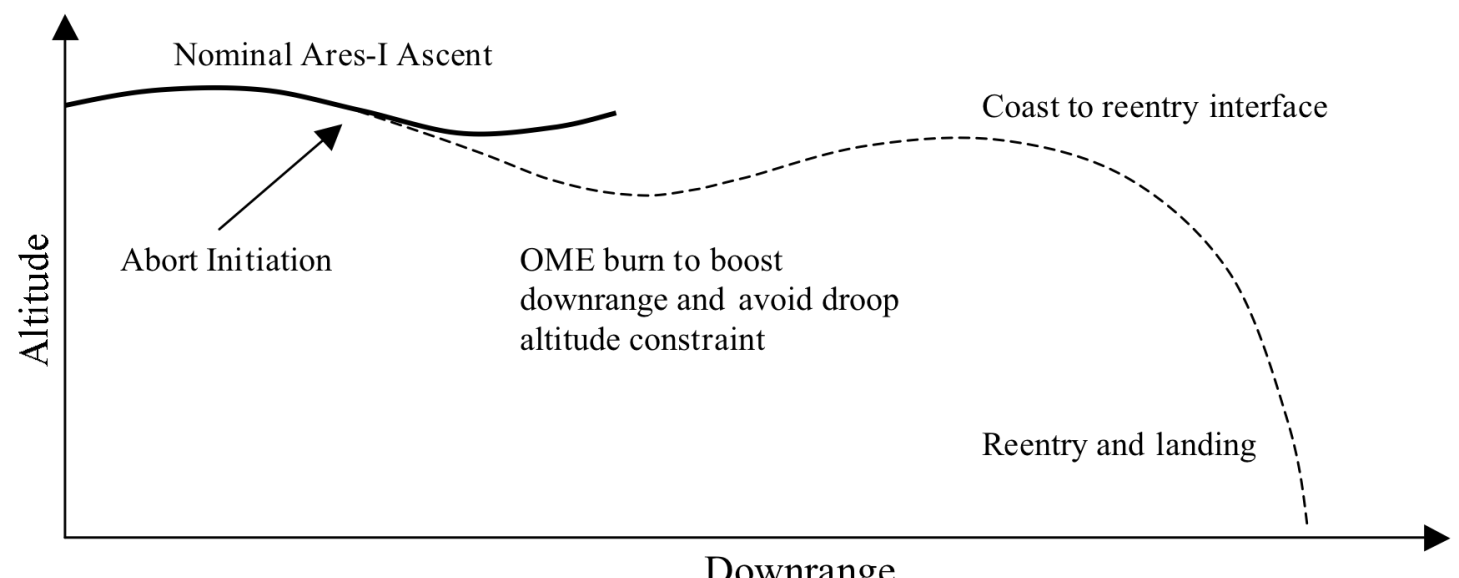

Figure 2. Targeted abort landing flight profile

The abort-to-orbit option, referred to as Mode IV aborts during Apollo ${ }^{2}$, uses the SM RCS system to separate the CEV from the Ares-I upper stage and then uses the OME to raise apogee altitude to approximately $100 \mathrm{nmi}$. The vehicle then coasts to apogee where it performs an insertion burn to circularize to a stable orbit. Like TAL aborts, ATO cases have an altitude constraint due to thermal heating. They also require substantially more delta- $V$ than TAL aborts. This option is generally considered the most desirable abort scenario as it allows for both the possible continuation of the nominal mission and a CONUS landing of the crew module. This later criteria is important as it provides for cheaper and safer recovery operations, and makes for easier refurbishment of the crew module. The phase sequence used to model the ATO sequence is shown in Table 3, and a notional flight profile is shown in Figure 3.

Table 3. Abort-to-orbit phase sequence

\begin{tabular}{|c|l|}
\hline Phase & Description \\
\hline Abort Initiation & $\begin{array}{l}\text { Abort is initiated at a give time }\left(\mathrm{t}_{0}\right) \text {. } \\
\text { The CEV state is assigned based on the interpolated CLV state at } \mathrm{t}_{0} .\end{array}$ \\
\hline $\begin{array}{c}\text { Separation } \\
\text { Burn Engine }\end{array}$ & CM is separated from SM and the vehicle drifts for 15 seconds. \\
\hline Coast to Apogee & $\begin{array}{l}\text { The main engine and auxiliary thrusters are fired to boost the vehicle's apogee altitude } \\
\text { to } 100 \text { nmi while maintaining an altitude above the droop altitude constraint. } \\
\text { the circularization burn, is chosen to give the best performance }\end{array}$ \\
\hline Circularization & The CEV circularizes using the main engine. \\
\hline
\end{tabular}

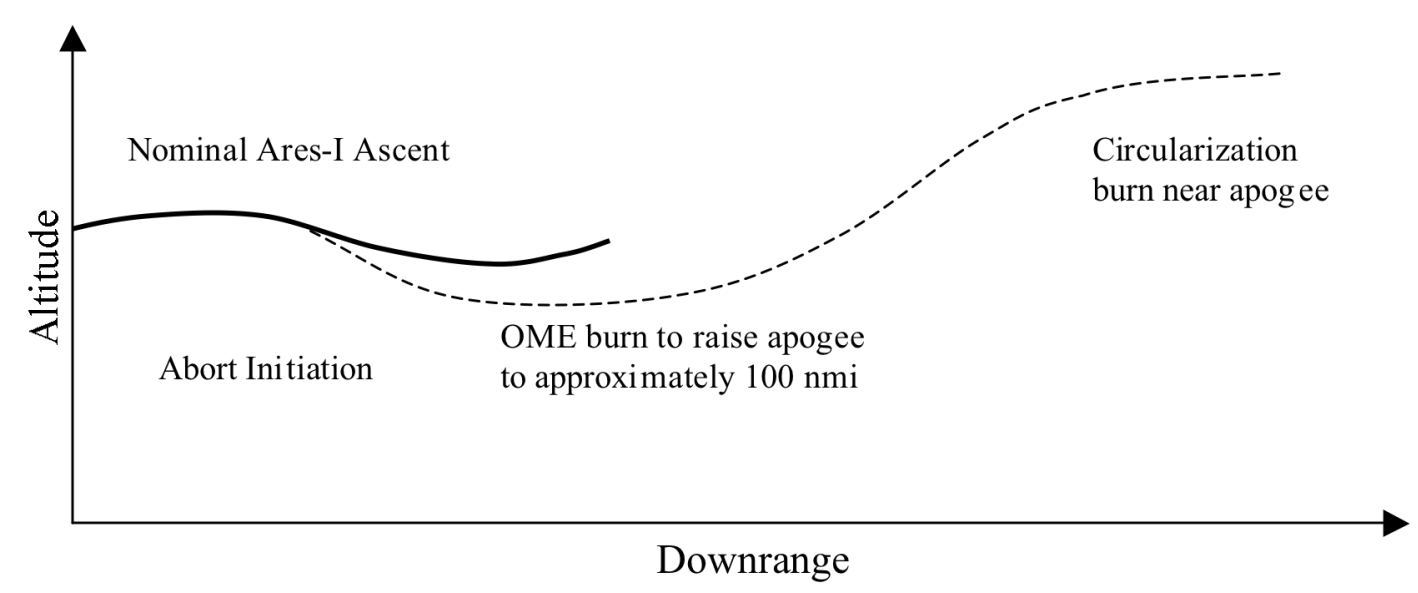

Figure 3. Abort-to-orbit flight profile 


\section{B. Trajectory Optimization Tools}

The 3DOF ascent abort analysis detailed in this report is conducted using the Optimal Trajectories via Implicit Simulation (OTIS) trajectory optimization software program, version $4^{3}$. The OTIS software program will optimize an aerospace vehicle trajectory given a well-defined, smooth objective function, assumptions on vehicle properties, and a predefined notion of the trajectory event sequence. Trajectory sequences are broken into phases. In a given phase, the vehicle configuration and environment are assumed constant (e.g. number of engines, atmospheric models, etc). The phase structures used to model UAS, TAL, and ATO aborts are shown in Tables 1, 2, and 3, respectively.

In the abort initiation phase, which is common to each abort mode, OTIS determines the earliest abort initiation time possible while satisfying all constraints imposed on the problem. Given an abort initiation time, OTIS performs a table lookup of the aerodynamic flight path coordinates (geodetic altitude, geodetic latitude, longitude, air-relative velocity, air-relative flight path angle, and azimuth) of the Ares I launch vehicle at the corresponding time. Since the Ares-I trajectory data used for this analysis begins with main engine ignition, the abort initiation time is referenced relative to the time of main engine ignition. Ares I trajectory histories developed during the second design analysis cycle are used in this analysis. Utilizing this table-lookup technique to start the OTIS problem at the time of abort initiation speeds up the convergence of OTIS since it is not continuously trying to optimize the trajectory prior to abort.

\section{Results}

The optimal propellant loading determined by OTIS for Max-TAL and Max-ATO given each propulsion system configuration examined is shown in Table 4. As expected, the optimal propellant loading increases with increasing thrust-to-weight ratio, since higher thrust-to-weight configurations can overcome the droop altitude constraint earlier, but then requires more delta- $\mathrm{V}$ capability to perform the abort. The corresponding time of earliest possible abort for each propellant loading is shown in Figures 4 and 5.

Table 4. Propellant loadings for minimum abort times with various thrust configurations

\begin{tabular}{|c|c|c|}
\hline Configuration & Max-TAL SM Propellant Loading (lbf) & Max-ATO SM Propellant Loading (lbf) \\
\hline $7500 \mathrm{lbf}$ & 5375.9 & 14470.1 \\
\hline $8300 \mathrm{lbf}$ & 5922.0 & 15110.2 \\
\hline $10000 \mathrm{lbf}$ & 6687.4 & 15670.1 \\
\hline $10800 \mathrm{lbf}$ & 7167.0 & 16156.8 \\
\hline $10980 \mathrm{lbf}$ & 7383.4 & 16423.0 \\
\hline
\end{tabular}

Max-ATO propellant loading results are shown in Figure 4. The two groupings represent TAL abort performance (circular markers) and ATO abort performance (square markers). The dashed and solid lines in Figures 4 and 5 are the results of previous abort performance analysis generated for the Crew Exploration Vehicle Project ${ }^{4}$. That study analyzed the abort delta- $\mathrm{V}$ requirement as a function of abort time and thrust-to-weight ratio, instead of using specific engine configurations. Some key assumptions have changed since that study; most notably the AresI insertion altitude, the drift time after separation from the launch vehicle, and the CEV mass properties. Despite such differences, these results agree well with those of the previous study. Each of the points shown in the MaxATO coverage chart represent the left-most bound of a sweep of abort initiation time. Using OTIS to minimize abort initiation time has made this easier to accomplish, whereas during the previous parametric sweeps of the previous study, convergence near the left-most bound of these curves was sometimes difficult.

The shaded region on the left side of the graphs indicates the region of feasible UAS aborts. Analysis of the untargeted abort splashdowns resulted in a latest feasible UAS abort occurring at about 561 seconds MET. In order to meet the abort exclusion zone requirements defined in Reference 1, the CEV must be capable of performing a TAL or ATO abort at this point. As Figure 4 indicates, the $7500 \mathrm{lbf}$ engine configuration would result in an abort coverage gap of about 1.5 seconds. The $8300 \mathrm{lbf}$ engine configuration just barely covers this gap, with less than 0.5 seconds of coverage overlap. Since this study is based on nominal launch vehicle performance and optimal performance of the CEV following an abort, there is a good chance that the $8300 \mathrm{lbf}$ configuration will be rendered inadequate by dispersion analysis. 


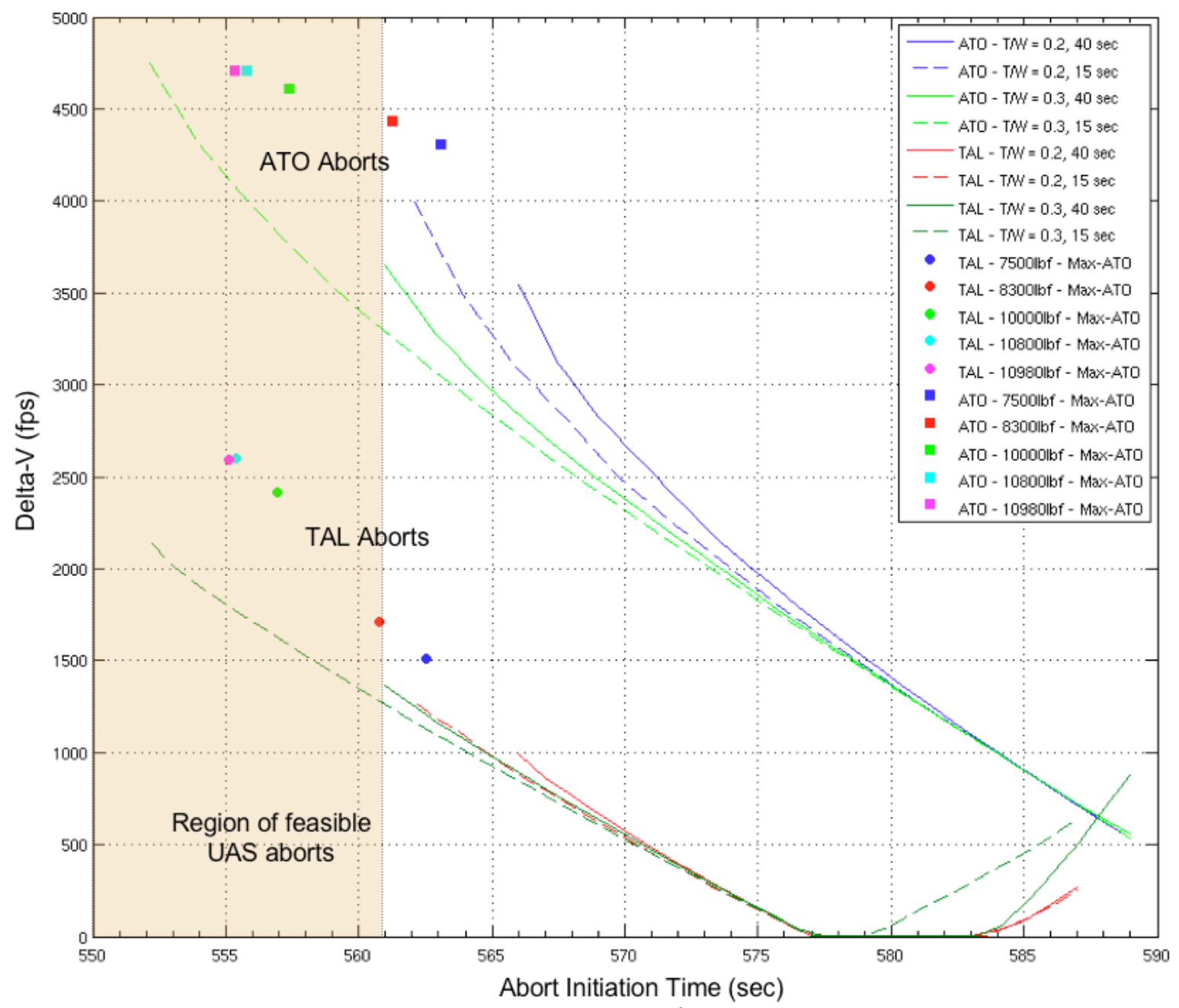

Figure 4. Abort delta-V vs. initiation time for nominal $51.6^{\circ}$ ascent with minimum abort times for ATOmaximized point designs

The Max-TAL propellant loading results (Fig. 5) indicate that less propellant can provide more abort coverage. Loaded with less propellant, these cases have a higher thrust-to-weight ratio for a given engine configuration. As a result, the TAL aborts can occur earlier since the greater thrust-to-weight ratio allows them to more readily avoid the droop altitude constraint. For instance, the $8300 \mathrm{lbf}$ engine configuration point that just barely provided abort mode overlap with Max-ATO propellant loading can provide about six seconds over overlap with Max-TAL propellant loading.

While the reduced propellant loading provides for earlier TAL aborts by increasing thrust-to-weight ratio, the decrease in delta-V capability delays the onset of the ATO window. In other words, the ATO aborts loaded for maximum TAL capability need the Ares-I launch vehicle to import more energy into the trajectory before the CEV can complete orbital insertion. When using the Max-ATO propellant loading, the ATO window for a given engine configuration opens only a fraction of a second later than the corresponding TAL window. When using the MaxTAL propellant loading, the ATO window opens substantially later. For instance, as Figure 5 shows, the opening of the ATO window for the $8300 \mathrm{lbf}$ engine configuration occurs over 15 seconds after the TAL window opening. 


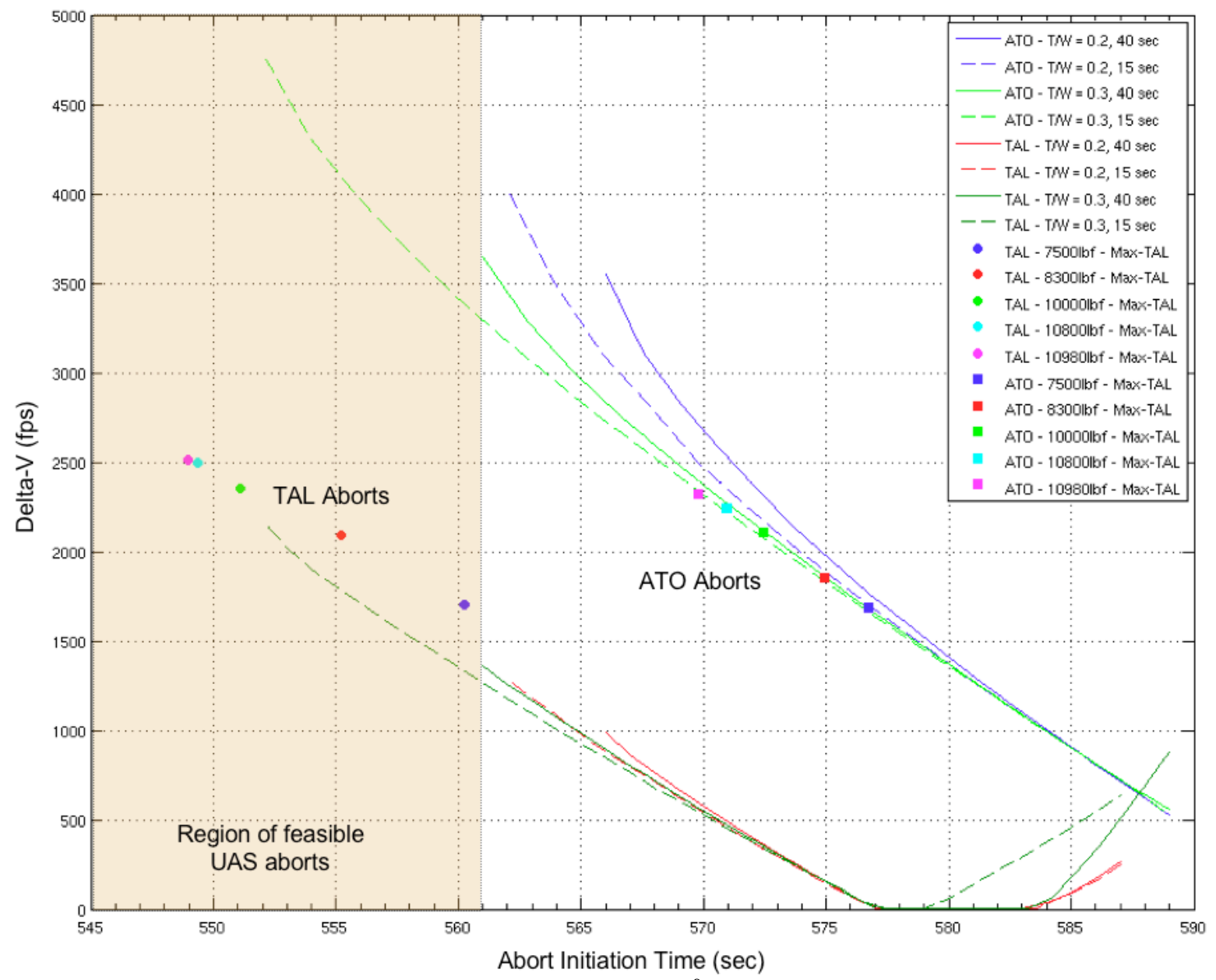

Figure 5. Abort delta-V vs. initiation time for nominal $51.6^{\circ}$ ascent with minimum abort times for TALmaximized point designs

\section{Conclusions}

The downrange abort exclusion zone (DAEZ) requirement for the CEV during ISS missions is a key driving requirement for both engine thrust magnitude and propellant loading. While the drive to provide ATO coverage as early as possible is reasonable, this option must be weighed against the delay in TAL abort coverage it causes. Given the assumptions used in this work, loading propellant that allows for the earliest possible ATO abort will delay the opening of TAL coverage beyond the end of the UAS abort window, resulting in a potential gap in abort coverage, and a violation of Constellation requirements ${ }^{1}$. Utilizing OTIS to minimize abort time has shown to be a successful approach to this problem, since the coupling of thrust-to-weight ratio and propellant loading allows OTIS to minimize the abort time while simultaneously finding a propellant-optimal trajectory for ATO and TAL aborts.

\section{References}

${ }^{1}$ Constellation Architecture Requirements Document, CxP 70000, 16 Aug. 2006.

${ }^{2}$ Henderson, E. M. and Butler, J. V., "Spacecraft Operational Abort Plan for Apollo 7 (Mission C). Volume 2: CSM Launch Aborts," NASA TM 69694, 19 July, 1968.

${ }^{3}$ Riehl, J. P., Paris, S. W., and Sjauw, W. K., "Comparison of Implicit Integration Methods for Solving Aerospace Trajectory Optimization Problems," AIAA 2006-6033, 21-24 Aug. 2006.

${ }^{4}$ Falck, R. D., Burke, L. M., and Gefert, L. P., "CEV RAC-2 TDS-04-012/Subtask 5: Late Ascent Abort Modeling Sensitivities Analysis,” NASA FltDyn-CEV-06-92, 11 Sept. 2006. 


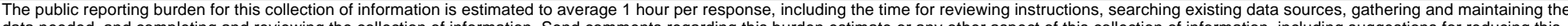

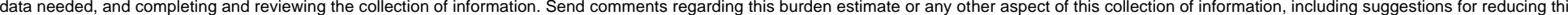

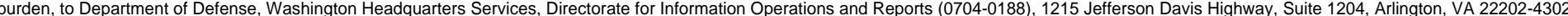

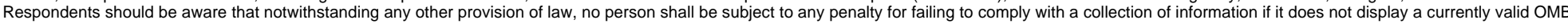
control number.

PLEASE DO NOT RETURN YOUR FORM TO THE ABOVE ADDRESS.

\section{REPORT DATE (DD-MM- $Y Y Y Y)$ \\ 2. REPORT TYPE \\ 3. DATES COVERED (From - To)}

01-12-2007

Technical Memorandum

\section{TITLE AND SUBTITLE}

Crew Exploration Vehicle Ascent Abort Trajectory Analysis and Optimization

\section{5a. CONTRACT NUMBER}

5b. GRANT NUMBER

5c. PROGRAM ELEMENT NUMBER

\section{AUTHOR(S)}

Falck, Robert, D.; Gefert, Leon, P.

\section{5d. PROJECT NUMBER}

5e. TASK NUMBER

5f. WORK UNIT NUMBER

WBS 644423.06.32.03.15.03

\section{PERFORMING ORGANIZATION}

REPORT NUMBER

E-16199

National Aeronautics and Space Administration

John H. Glenn Research Center at Lewis Field

Cleveland, Ohio 44135-3191

9. SPONSORING/MONITORING AGENCY NAME(S) AND ADDRESS(ES)

National Aeronautics and Space Administration

Washington, DC 20546-0001

\section{DISTRIBUTIONIAVAILABILITY STATEMENT}

Unclassified-Unlimited

Subject Category: 15

Available electronically at http://gltrs.grc.nasa.gov

This publication is available from the NASA Center for AeroSpace Information, 301-621-0390

\section{SPONSORINGIMONITORS ACRONYM(S) \\ NASA \\ 11. SPONSORING/MONITORING REPORT NUMBER \\ NASA/TM-2007-214996; AIAA-2007- 6775}

\section{SUPPLEMENTARY NOTES}

\section{ABSTRACT}

The Orion Crew Exploration Vehicle is the first crewed capsule design to be developed by NASA since Project Apollo. Unlike Apollo, however, the CEV is being designed for service in both Lunar and International Space Station missions. Ascent aborts pose some issues that were not present for Apollo, due to its launch azimuth, nor Space Shuttle, due to its cross range capability. The requirement that a North Atlantic splashdown following an abort be avoidable, in conjunction with the requirement for overlapping abort modes to maximize crew survivability, drives the thrust level of the service module main engine. This paper summarizes 3DOF analysis conducted by NASA to aid in the determination of the appropriate propulsion system for the service module, and the appropriate propellant loading for ISS missions such that crew survivability is maximized.

\section{SUBJECT TERMS}

Abort trajectories; Trajectory optimization; Crew exploration vehicle

\section{SECURITY CLASSIFICATION OF}

a. REPORT

$\mathrm{U}$

\section{b. ABSTRACT} $\mathrm{U}$

\section{LIMITATION OF} ABSTRACT

UU

18. NUMBER
OF
PAGES
13

19a. NAME OF RESPONSIBLE PERSON

STI Help Desk (email:help@sti.nasa.gov)

19b. TELEPHONE NUMBER (include area code) 301-621-0390 

